\title{
MILD MODIFICATION METHOD FOR THE GENERATION OF MESOPOROSITY IN SYNTHETIC AND NATURAL MORDENITE
}

\author{
Wondimagegne Mamo ${ }^{\mathrm{a}}$, Yaregal Awoke ${ }^{\mathrm{a}}$, Yonas Chebude ${ }^{\mathrm{a}}$ and Isabel Diaz ${ }^{\mathrm{a}, \mathrm{b} *}$ \\ ${ }^{a}$ Chemistry Department, Addis Ababa University, Addis Ababa, Ethiopia \\ ${ }^{\mathrm{b}}$ Instituto de Catálisis y Petroleoquímica, CSIC, c/Marie Curie 2, 28049 Madrid, Spain
}

(Received May 8, 2014; revised December 23, 2014)

\begin{abstract}
Zeolites are widely used as acid catalysts for the synthesis of fine chemicals in industrial processes. However, in most cases, diffusion limitations in the microporous network of zeolites prevents a good catalytic performance. In this sense, in the course of our research we have modified synthetic and natural mordenite zeolites by mild dealumination/desilication process to obtain mesoporosity. Commercial mordenite $(\mathrm{CBV} 21 \mathrm{~A} \mathrm{Si} / \mathrm{Al}=10.5)$, and natural mordenite from Ethiopia $(\mathrm{Si} / \mathrm{Al}=6.2)$ have been treated under mild conditions $(\mathrm{pH}=6)$ in order to maintain high crystallinity in the final zeolites. The impact of this mild treatment (based on ammonium acetate) is remarkable in the synthetic mordenite, creating good degree of mesoporosity while maintaining the bulk Si/Al ratio and crystallinity of the sample. In the case of the natural mordenite, the treatment leads to strong increase in the crystallinity of the sample, although only small mesoporosity is created. All samples were characterized by X-ray diffraction (XRD), inductively coupled plasma atomic emission spectroscopy (ICP-AES), $\mathrm{N}_{2}$ adsorption-desorption isotherms and transmission electron microscopy (TEM).
\end{abstract}

KEY WORDS: Zeolites, Mordenite, Natural mordenite, Modification, Mesoporous zeolites

\section{INTRODUCTION}

Zeolites are of great scientific and technological interest because of their unique intrinsic properties such as high surface area, excellent thermal stability, tunable surface properties and shape selectivity [1]. Catalytic studies involving zeolite crystals with precisely controlled compositions and crystal sizes are of extreme importance in elucidating the type of the shapeselective phenomena derived from the particular pore architecture of this class of microporous materials [2]. Structures with 8-ring, 10-ring, or 12-ring channel apertures are the most common and these are usually known as small-, medium-, and large-pore zeolites, respectively [3]. Large pore zeolites such as faujasite, mordenite, and beta zeolite play an important role in the design of hydrocarbon conversion catalysts [4]. Mordenite is one of the six most abundant zeolites in nature that is used commercially. Only 6 out of more than 60 natural zeolites commonly occur in large tuff: analcime (ANA), chabazite (CHA), clinoptilolite (HEU), erionite (ERI), mordenite (MOR), and phillipsite (PHI); ferrierite (FER) occurs in a few large tuff. Each of the seven zeolites have also been synthesized, but only mordenite and ferrierite are manufactured in large quantities [5]. Mordenite zeolite was first described in 1864 by Henry How [6]. He named it after the small community of Morden, Nova Scotia, Canada, along the Bay of Fundy, where it was first found. Mordenite is orthorhombic $(\mathrm{Cmcm}, \mathrm{a}=18.256 \AA, \mathrm{b}=20.534 \AA, \mathrm{c}=7.542 \AA, \alpha$ $=\beta=\gamma=90^{\circ}$ ) [7]. The molecular formula of mordenite includes a $\mathrm{Si} / \mathrm{Al}$ ratio that in natural samples varies between 4 and 6 . Its high ratio of silicon to aluminum atoms makes it more resistant to attack by acids than most other zeolites. Consequently, a significant fraction of the framework aluminum can be removed by acid leaching without altering the basic structure [8]. Mordenite consists of 12-membered ring (MR) pore channels of $0.67 \times 0.70 \mathrm{~nm}$ interconnected by 8 -MR pores of $0.34 \times 0.48 \mathrm{~nm}$ [9]. Because the 8 -MR channels are too small for most molecules to enter, it is generally considered a one-dimensional pore system, inducing singlefile diffusion [10]. Such a pore size and shape limits the application of mordenite to large molecules. To improve physical transport in the one-dimensional channels, mordenite zeolites

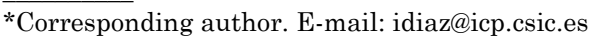


are typically subjected to dealumination post treatments [11]. Although dealumination indeed has proven to generate additional mesoporosity, this approach directly affects the acidic properties of the zeolite structure, due to the extraction of aluminum from the zeolite framework. The facilitated transport acquired by the introduction of mesoporosity is partially cancelled out by the reduced density of acid sites. Boveri et al. investigated the impact of steaming and acid leaching on the physicochemical and catalytic properties of a commercial mordenite catalyst [12]. Mesoporosity in zeolites can also be created through desilication, which consists of a controlled extraction of silicon from the framework, by treating the zeolite in an alkaline medium. This treatment produced extended mesoporosity in zeolite crystals, with a minor effect on their acidity. Several publications on this subject have recently emerged, especially focusing on the MFI and MOR type zeolites [13, 14]. Recent studies undertaken with dicarboxylic acids such as oxalic acid indicated that they had potential for effecting large reductions in overall acidity with little loss in crystallinity and zeolite sorption properties [15-17]. The objective of our work has been to develop a procedure based on ammonium acetate treatment to prepare zeolites with improved acidity and mesoporosity while maintaining high levels of crystallinity. In the present work, we present a systematic study on the mild modification of synthetic and natural (obtained from Ethiopia) mordenites. The influence of the several modification parameters on the structural, chemical and textural properties of the mordenite samples was studied.

\section{Starting materials and zeolites}

\section{EXPERIMENTAL}

Synthetic mordenite (herein called SMOR) CBV21A ( $\mathrm{Si} / \mathrm{Al}=10.5)$ was obtained from ZEOLYST. Natural zeolite sample ET-5 collected from Tigrai region in Ethiopia was obtained from the School of Earth Sciences, Addis Ababa University. The natural zeolite sample ET-5 was used after separation of the mixtures present in the rock. Sample ET-5 contains the mixture of mordenite, ilmenite $\left(\mathrm{FeTiO}_{3}\right)$ and quartz. These mixtures were separated as follows: initial mineral mixture and water were mixed with ratio of $2 \mathrm{~g} / 200 \mathrm{~g}$, at a temperature of 303-313 K, and with contact time of 15-30 min, a suspension was formed in an ultrasonic bath. The suspension with lower density was filtered out using suction filtration, dried in an oven at $383 \mathrm{~K}$ and characterized by X-ray diffraction to identify the enriched mordenite phase sample, hereafter called NMOR (Figure 1).

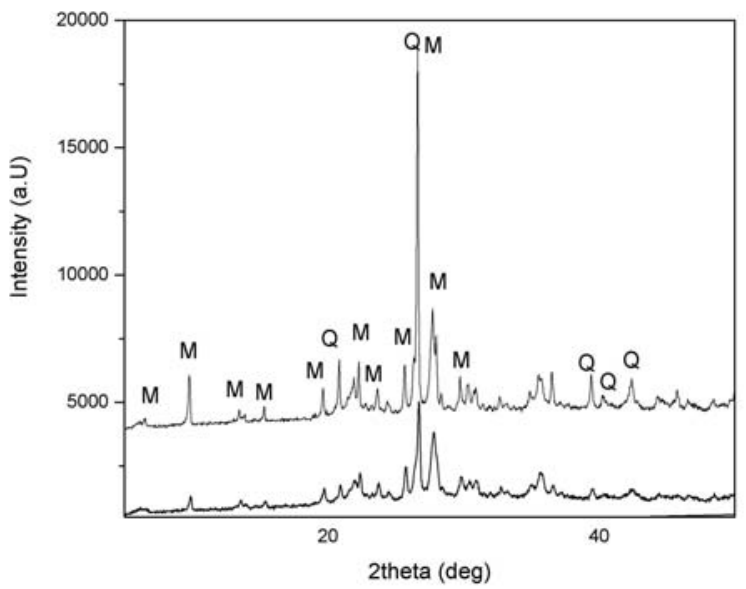

Figure 1. XRD ET-5 (above) and NMOR after separation (below). M: mordenite, Q: quartz, remaining intensities correspond to Ilmenite.

Bull. Chem. Soc. Ethiop. 2015, 29(1) 


\section{Modification methods}

Table 1 collects the different treatments carried out in both synthetic and natural mordenites. As an example, ammonium acetate treatment details as follows: $2 \mathrm{~g}$ of zeolite was stirred in $26 \mathrm{~mL}$ of $3 \mathrm{M}$ ammonium acetate solution at $25{ }^{\circ} \mathrm{C}$ for $30 \mathrm{~min}$. Then $12 \mathrm{~mL}$ of $2.4 \mathrm{M} \mathrm{NH}_{4} \mathrm{~F}$ aqueous solution was added drop-wise on the previous suspension and stirred at $80{ }^{\circ} \mathrm{C}$. After complete addition in the solution, the suspension was kept stirring for $30 \mathrm{~min}$, followed by filtering and washing (twice) with hot deionized water. Finally, the resulting solid was dried at $100{ }^{\circ} \mathrm{C}$ for 12 hours and calcined at $550{ }^{\circ} \mathrm{C}$ for 6 hours to obtain modified H-MOR zeolite.

Table 1. Modification treatments conducted for synthetic (SMOR) and natural (NMOR) mordenites.

\begin{tabular}{|c|c|c|}
\hline Sample & Treatment & Sample \\
\hline SMOR & Parent & NMOR \\
\hline SM-M1 & $3 \mathrm{M} \mathrm{NH}_{4} \mathrm{Ac}+2.4 \mathrm{M} \mathrm{NH}_{4} \mathrm{~F}$ & NM-M1 \\
\hline SM-M2 & $3 \mathrm{M} \mathrm{NH}_{4} \mathrm{Ac}$ & NM-M3 \\
\hline SM-M3 & $3 \mathrm{M} \mathrm{NH}_{4} \mathrm{Cl}$ & NM-M4 \\
\hline SM-M4 & $1 \mathrm{M} \mathrm{NH}_{4} \mathrm{Ac}$ & NM-M5 \\
\hline SM-M5 & $1 \mathrm{M} \mathrm{NH}_{4} \mathrm{Cl}$ & NM-M6 \\
\hline SM-M6 & $1 \mathrm{M} \mathrm{NH}_{4} \mathrm{Ac}+2.4 \mathrm{M} \mathrm{NH}_{4} \mathrm{~F}$ & NM-M7 \\
\hline SM-M7 & $3 \mathrm{M} \mathrm{NH}_{4} \mathrm{Cl}+2.4 \mathrm{M} \mathrm{NH}_{4} \mathrm{~F}$ & NM-M8 \\
\hline SM-M8 & $1 \mathrm{M} \mathrm{NH}_{4} \mathrm{Cl}+2.4 \mathrm{M} \mathrm{NH}_{4} \mathrm{~F}$ & \\
\hline
\end{tabular}

\section{Characterization techniques}

The structural, chemical, and textural studies were carried out at the Institute of Catalysis and Petroleochemistry, CSIC (Madrid, Spain). Powder X-ray diffraction (XRD) patterns were collected with X'Pert Pro PANalytical. Inductively coupled plasma optical emission spectrometry, (ICP-OES) (Optima 3300 DV model) was used to determine the chemical composition. Desegregation of the sample was obtained by alkaline fusion in an automatic fusion. Digestion was performed in Teflon vessels using an acid mixture of $\mathrm{HCl}, \mathrm{HNO}_{3}, \mathrm{HF}$ and $\mathrm{H}_{3} \mathrm{PO}_{4} . \mathrm{N}_{2}$ adsorption isotherms were measured at $-196{ }^{\circ} \mathrm{C}(77 \mathrm{~K})$ on Micromeritics ASAP 2420 and the micropore surface area and volumes were calculated by the Brunauer-Emmett-Teller (BET) method. JEOL $2100 \mathrm{~F}$ transmission electron microscope (TEM) operating at $200 \mathrm{kV}$ was used to evaluate and locate the presence of mesoporosity inside the crystalline zeolites. For the TEM observations, the samples are crushed and dispersed in ethanol, few drops are placed on a holey copper grid.

\section{RESULTS AND DISCUSSION}

Mordenite was chosen for modification because it has a natural analogue in Ethiopia. The aim of the treatments studied is to find an optimum method to slightly dealuminate mordenite zeolites while creating small amount of mesopores and increasing the hydrophobicity. Table 1 shows the sample codes along with each particular treatment. The novelty of this work lies on the use of ammonium acetate $\left(\mathrm{NH}_{4} \mathrm{Ac}\right)$ followed by ammonium fluoride $\left(\mathrm{NH}_{4} \mathrm{~F}\right)$ treatment as it is done at $\mathrm{pH}=6$ (mild treatment). Previous experiments in our group pointed out that this particular treatment may lead to the creation of small mesoporosity without large variation in $\mathrm{Si} / \mathrm{Al}$ ratio and without losing crystallinity. In particular, $\mathrm{NH}_{4} \mathrm{Ac}$ treatment $(\mathrm{pH}=6)$ has proven to be very efficient in the generation of mesopores in zeolite $\mathrm{Y}$ [18]. The $\mathrm{NH}_{4} \mathrm{Ac}$ step removes the aluminum, and according to the literature, it does this selectively from the surface via 'chelating' effect of acetate ion. In order to evaluate the above mentioned effect, we have studied the same process in ammonium chloride form. On the other hand, we believe that the $\mathrm{NH}_{4} \mathrm{~F}$ step helps in washing off the silicon that remains weakly bonded to the framework of the zeolite, by forming hexafluorosilicate. As a consequence, only slight change in the $\mathrm{Si} / \mathrm{Al}$ ratio is expected. Finally, treatments with only $1 \mathrm{M}$ ammonium solutions were conducted in order to 
compare our methods with the conventional ion exchange methods. We believe that the conventional $\mathrm{NH}_{4} \mathrm{Cl}$ step followed by calcination helps in washing off the possible extra framework species as well as created small mesoporosity. In all the cases, the modified mordenite was calcined at $500{ }^{\circ} \mathrm{C}$ for $6 \mathrm{~h}$ prior to characterization.

X-ray diffraction (XRD) patterns of the parent and one of the treated samples of synthetic and natural mordenite are shown in Figure 2. As it can be seen, the crystallinity of the parent zeolite is maintained upon treatments since no important changes in the patterns are observed. In order to quantify this structural modification, the values of the degree of crystallinity, $\mathrm{C}_{\mathrm{XRD}}$, of the modified samples have been calculated using the equation 1, assuming that parent SMOR and NMOR as $100 \%$ crystallinity [19]. The results are quoted in Table 2.

Crystallinity $\left(\% \mathrm{C}_{\mathrm{XRD}}\right)=\frac{\text { Areas of all the diffraction peaks of treated samples }}{\text { Areas of all the diffraction peaks of reference }} \times 100 \%$

Quantitative analysis of diffraction data indicates a decrease of up to $\sim 50 \%$ in crystallinity in the case of the synthetic mordenites, whereas in the natural mordenite crystallinity increases from $170-200 \%$ in the modified samples.

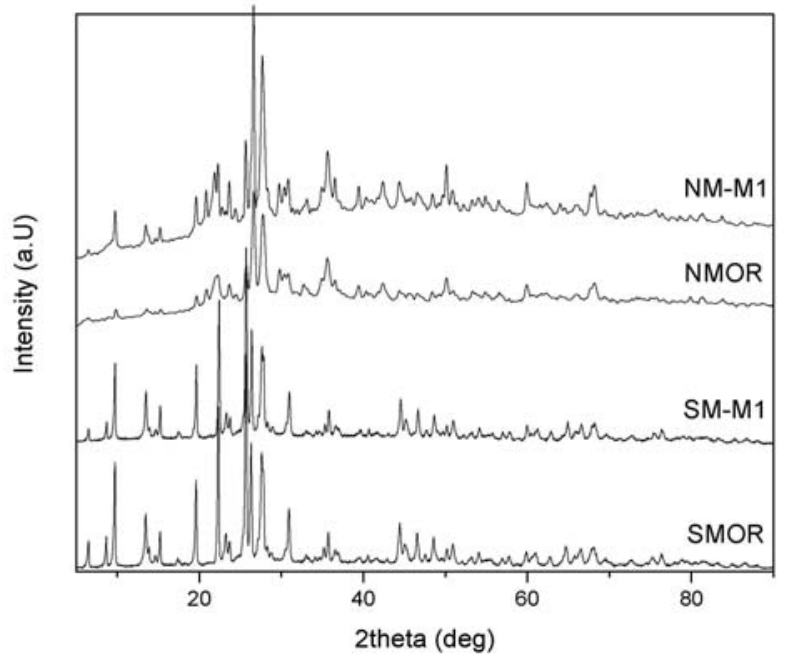

Figure 2. X ray diffraction (XRD) patterns of parent mordenites synthetic, SMOR, and natural, NMOR, along with ammonium acetate followed by ammonium fluoride treatments of synthetic, SM-M1, and natural, NM-M1, mordenites.

Table 2. Degree of crystallinity $\left(\mathrm{C}_{\mathrm{XRD}}\right)$ of the modified samples.

\begin{tabular}{|c|c|c|c|}
\hline Sample & C XRD $_{\text {X\%) }}$ & Sample & C XRD (\%) \\
\hline SMOR & 100 & NMOR & 100 \\
\hline SM-M1 & 88 & NM-M1 & 203 \\
\hline SM-M2 & 63 & NM-M2 & 177 \\
\hline SM-M3 & 118 & NM-M3 & 193 \\
\hline SM-M4 & 57 & NM-M4 & 189 \\
\hline SM-M5 & 84 & NM-M5 & 190 \\
\hline SM-M6 & 55 & NM-M6 & 93 \\
\hline SM-M7 & 52 & NM-M7 & 104 \\
\hline SM-M8 & 94 & NM-M8 & \\
\hline
\end{tabular}

Bull. Chem. Soc. Ethiop. 2015, 29(1) 
The general increment of crystallinity observed in natural mordenites is probably due to the substitution reactions during the treatments that after calcination leads to more uniform and "clean" microstructure. In the case of SM-M3, treated with $3 \mathrm{M} \mathrm{NH}_{4} \mathrm{Cl}$, higher crystallinity is obtained, most probably due to the washing off of the extra framework aluminum species. In general terms, the treatments involving acetate show larger decrease of crystallinity; this indicates that the framework is partially dissolved upon dealumination. Only in the case when the $\mathrm{NH}_{4} \mathrm{Ac}$ process (responsible for dealumination) is followed by $\mathrm{NH}_{4} \mathrm{~F}$ treatment (desilication), a high degree of crystallinity is maintained, most probably due to the "restructuring" effect given by the removal of the defects created in the first step, i.e. by the removal of remaining silicon that are not completely condensed. Besides, it is possible to observe an increase in intensities of the peaks at low diffraction angles after dealumination, related to the enhanced hydrophobicity, due to the loss of acid sites. Even after heavy dealumination, $50 \%$ crystallinity is still retained. In summary, a crystallinity of $88 \%$ was found for SM-M1 sample, corresponding to our mild method. In conclusion, the crystallinity and morphology of mordenite crystals are largely preserved upon dealumination, supported by XRD results. ICP analyses provide the resulting $\mathrm{Si}$ and $\mathrm{Al}$ content in the samples, regardless of the environment. Both, the tetrahedral $\mathrm{Si}$ and $\mathrm{Al}$ species as well as defects and extra framework species (octahedral) are counting in the $\mathrm{Si} / \mathrm{Al}$ ratio obtained by ICP. The results in Table 3 indicate a mild dealumination of all synthetic modified samples (the $\mathrm{Si} / \mathrm{Al}$ ratio increased from 10.5 to 12.5 maximum). Removal of aluminum also leads to a decrease in the total number of active sites; therefore, the aim of a second step in M1 treatment is to selectively remove silicon to balance the final acidity.

Table 3. ICP data collected for the synthetic and modified synthetic mordenites.

\begin{tabular}{|c|c|c|c|}
\hline Sample & Si/Al & Sample & Si/Al \\
\hline SMOR & 10.5 & NMOR & 6.2 \\
\hline SM-M1 & 11.5 & NM-M1 & 6.4 \\
\hline SM-M2 & 11.4 & NM-M2 & 6.5 \\
\hline SM-M3 & 11.2 & NM-M3 & 6.2 \\
\hline SM-M4 & 11.1 & NM-M4 & 6.1 \\
\hline SM-M5 & 11.1 & NM-M5 & - \\
\hline SM-M6 & 11.7 & NM-M6 & 6.4 \\
\hline SM-M7 & 12.5 & NM-M7 & 6.6 \\
\hline SM-M8 & 11.4 & NM-M8 & 6.6 \\
\hline
\end{tabular}

In the natural modified samples, a slight increase, i.e. $\sim 5 \%$ in the $\mathrm{Si} / \mathrm{Al}$ ratio can be observed in general terms with the exception of the samples NM-M3 $\left(3 \mathrm{M} \mathrm{NH}_{4} \mathrm{Cl}\right)$ and NM-M4 $(1 \mathrm{M}$ $\mathrm{NH}_{4} \mathrm{Ac}$ ). The isotherms of the parent and modified synthetic and natural mordenites are plotted in Figures $3 \mathrm{~A}$ and $3 \mathrm{~B}$, respectively. The isotherms belong to the typical microporous materials type IV curves [20]. The hysteresis loops at high relative pressures indicate the presence of some extra porosity broadened in diameter. The sudden $\mathrm{N}_{2}$ uptake is attributed to the capillary condensation occurring when bottle neck type of porosity is present. This may lead to think that it is the case when some mesopores are created within a microporous structure; however, the presence of the same hysteresis loop in the parent mordenite does not allow the conclusion whether we have achieved mesoporosity combined with the uniform micropore system of mordenite. The adsorption/desorption branches in $\mathrm{N}_{2}$ physisorption of natural mordenite samples are similar (Figure 3B), again belonging to type IV isotherm. In these cases, the hysteresis loops are not closed, probably due to the presence of other ions or impurities filling the pores of the natural zeolites. 

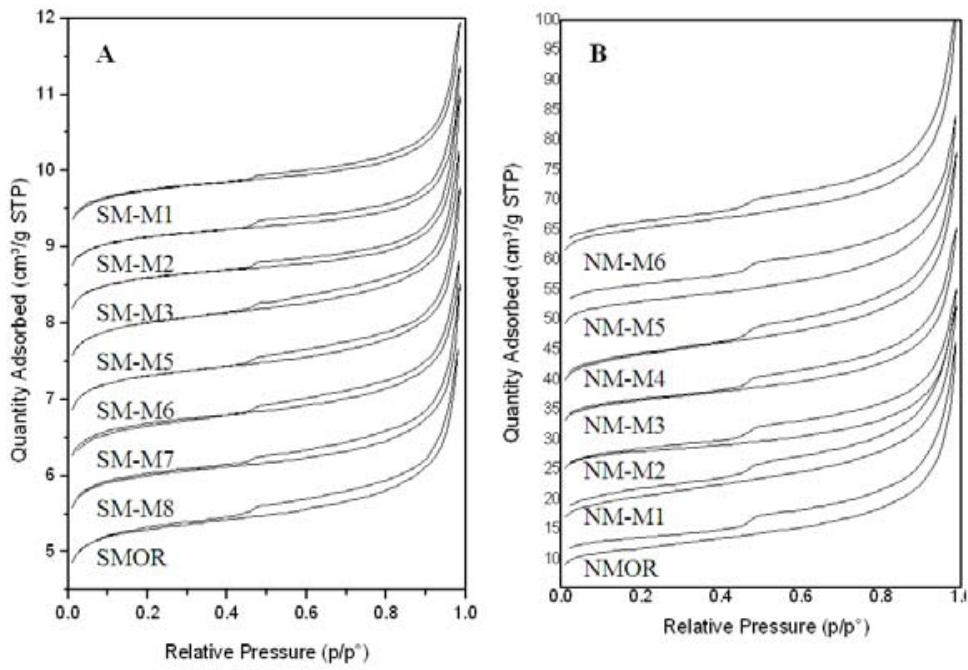

Figure 3. $\mathrm{N}_{2}$ isotherms of synthetic (A) and natural (B) modified samples.

Table 4 shows the textural properties of the synthetic modified samples. In all cases, the micropore volume and the surface area increased probably induced by an appreciable change in the pore size distribution. In addition, the external surface area is enlarged, which can be attributed to the presence of mesoporosity and surface roughness during the treatment. The treatments with higher concentrations of ammonium acetate or ammonium chloride (M1 to M5) appear to give the best combination of microporosity, high surface and external area, and high mesopore volume of the synthetic mordenite. But again, no clear evidences of mesoporosity related to a particular treatment could be extracted.

Table 4. Textural properties of synthetic mordenite and modified synthetic mordenite.

\begin{tabular}{|c|c|c|c|c|c|c|}
\hline \multirow{3}{*}{ Sample } & \multicolumn{3}{|c|}{ Surface area, $\mathrm{m}^{2} / \mathrm{g}$} & \multicolumn{3}{c|}{ Pore volume, $\mathrm{cm}^{3} / \mathrm{g}$} \\
\cline { 2 - 7 } & Total & Micro & Meso. & Total & Micro & Meso. \\
\cline { 2 - 7 } & BET & t-plot & t-plot & SP & t-plot & t-plot \\
\hline SMOR & 455 & 430 & 25 & 0.25 & 0.19 & 0.06 \\
\hline SM-M1 & 492 & 468 & 24 & 0.27 & 0.20 & 0.07 \\
\hline SM-M2 & 492 & 468 & 24 & 0.27 & 0.20 & 0.07 \\
\hline SM-M3 & 502 & 476 & 26 & 0.28 & 0.20 & 0.07 \\
\hline SM-M4 & 488 & 461 & 27 & 0.27 & 0.20 & 0.07 \\
\hline SM-M5 & 468 & 449 & 19 & 0.26 & 0.20 & 0.07 \\
\hline SM-M6 & 440 & 422 & 18 & 0.24 & 0.18 & 0.06 \\
\hline SM-M7 & 470 & 451 & 19 & 0.257 & 0.19 & 0.06 \\
\hline
\end{tabular}

Table 5 shows the textural properties of natural modified samples. After treatment in all cases, the micropore volume increased from 0.01 to $0.05 \mathrm{~cm}^{3} \mathrm{~g}^{-1}$ and the surface area from 43 to $122 \mathrm{~m}^{2} \mathrm{~g}^{-1}$. These results suggest that the desired transformation of micropores to mesopores may not have occurred, because the extraction of $\mathrm{Al}$ atoms from the mordenite framework produces only bigger micropores. The treatment appears to give the good increment of microporosity, high surface and external area, and low mesopore volume. In contrast, the textural data were not as good as expected like the synthetic one, probably because the $\mathrm{Si} / \mathrm{Al}$ molar ratio of the starting material was not in the optimal range. 
Mild modification method for generation of mesoporosity in synthetic and natural mordenite 101

Table 5. Textural properties of the natural and modified natural mordenite samples.

\begin{tabular}{|c|c|c|c|c|c|c|}
\hline \multirow{3}{*}{ Sample } & \multicolumn{3}{|c|}{ Surface area, $\mathrm{m}^{2} / \mathrm{g}$} & \multicolumn{3}{c|}{ Pore volume, $\mathrm{cm}^{3} / \mathrm{g}$} \\
\cline { 2 - 7 } & Total & Micro & Meso. & Total & Micro & Meso. \\
\cline { 2 - 7 } & BET & t-plot & t-plot & SP & t-plot & t-plot \\
\hline NMOR & 43 & 26 & 17 & 0.06 & 0.01 & 0.05 \\
\hline NM-M1 & 110 & 91 & 19 & 0.09 & 0.04 & 0.05 \\
\hline NM-M2 & 111 & 98 & 13 & 0.08 & 0.04 & 0.04 \\
\hline NM-M3 & 108 & 92 & 16 & 0.08 & 0.04 & 0.04 \\
\hline NM-M4 & 122 & 103 & 19 & 0.09 & 0.05 & 0.05 \\
\hline NM-M5 & 96 & 79 & 17 & 0.08 & 0.03 & 0.05 \\
\hline NM-M6 & 110 & 92 & 18 & 0.09 & 0.04 & 0.05 \\
\hline
\end{tabular}
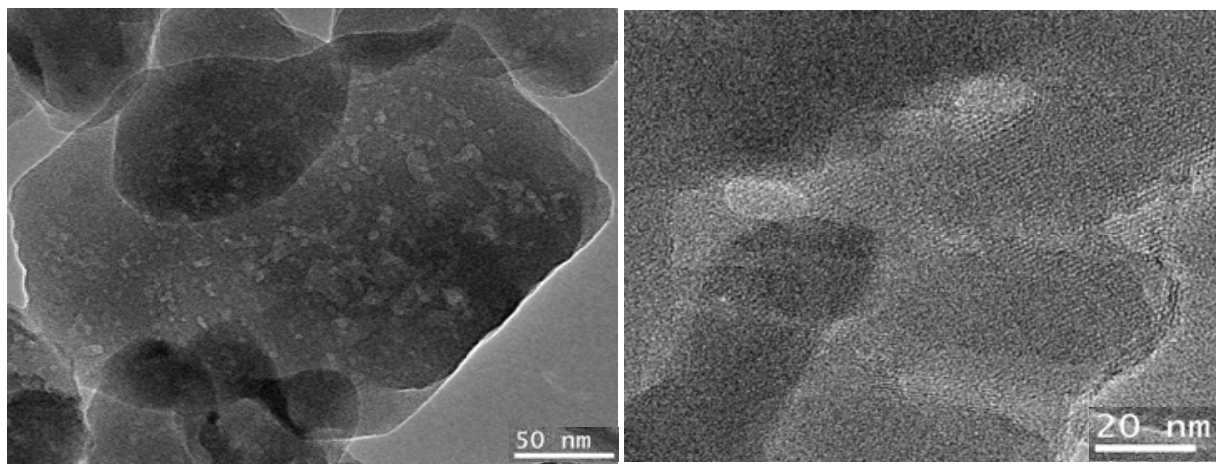

Figure 4. Sample SM-M1: (A) Low magnification TEM image where an entire crystal of MOR can be observed, with clear random contrasts due to mesopore formation (B). High magnification TEM image where the microstructure of MOR can be observed around a clear mesopore.

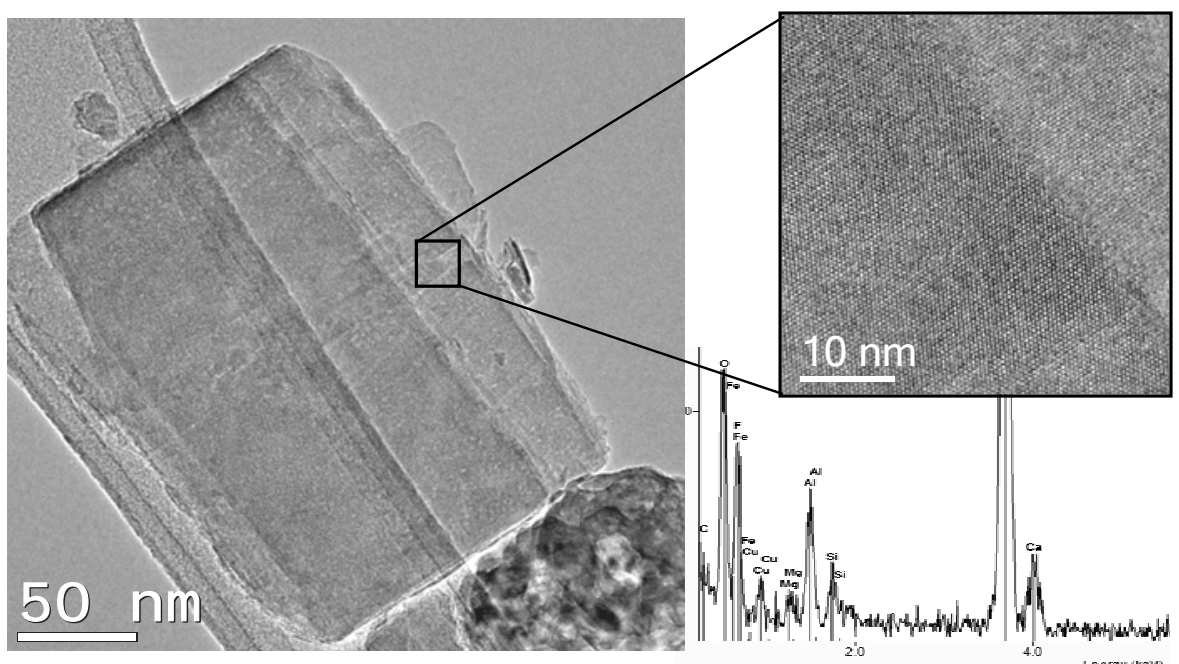

Figure 5. TEM images of NM-M1 at different magnifications. EDX spectrum shows the elemental composition of this particular crystal.

Bull. Chem. Soc. Ethiop. 2015, 29(1) 
According to the above described results, the presence of mesopores could not be easily demonstrated. Transmission electron microscopy (TEM) offers magnification, which allows identifying the zeolitic structure, and contrast due to electron density, which should enable observing areas with less population of atoms (i.e. mesopores). Figures 4 and 5 show the TEM images of SM-M1 and NM-M1, respectively. The images show mesopores with few $\mathrm{nm}$ in dimension, as interruptions of the lattice planes of the zeolite. Thus, the TEM investigations of all the materials revealed that a crystalline material with mesopores was obtained after the treatment in the cases of SM-M1, SM-M3 and SM-M7, whereas in SM-M2, M4, M5 and M6, no remarkable presence of mesopores could be observed. SM-M3 seemed to show larger mesopores and rather open to the surface instead of "bubbles" type of holes inside the microporous network, which is clearly observed in SM-M1. SM-M7 shows a high degree of dissolution within the crystals, thus a lower degree of crystallinity as it was already predicted by a $51 \%$ degree of crystallinity, calculated from the XRD pattern. In terms of treatment, the three samples refer to high concentration of ammonium salt (3 M): SM-M1, $3 \mathrm{M} \mathrm{NH}_{4} \mathrm{Ac}+\mathrm{NH}_{4} \mathrm{~F}$; SM-M3, $3 \mathrm{M} \mathrm{NH}_{4} \mathrm{Cl}$ only, and SM-M7, $3 \mathrm{M} \mathrm{NH}_{4} \mathrm{Cl}+\mathrm{NH}_{4} \mathrm{~F}$.

In the case of natural MOR, sample NM-M1, with the two step treatment, was observed in the TEM. Figure 5 shows representative images of this sample, which despite the heterogeneity allowed observing the typical mordenite structure along with some mesoporosity within the microporosity. Energy-dispersive X-ray spectroscopy (EDX) analysis also shows the presence of metals such as $\mathrm{Fe}$, along with the expected cations related to the zeolite $\mathrm{Mg}, \mathrm{Ca}(\mathrm{Cu}$ comes from the grid where the sample is prepared for TEM observations). Thus, the natural zeolite comprise significant amount of iron embedded naturally in the crystals. As a conclusion we may say that the treatments in the case of natural mordenites need further optimization including purification if the samples are to be used as catalysts.

\section{CONCLUSIONS}

The novel ammonium acetate treatment is the most suitable dealumination method which fully maintains the zeolite crystallinity. It is an effective means of modifying the acidity and pore size of zeolites in a controlled and predictable manner without losing the crystallinity. The improved acidity and porosity of these systems could also improve the catalytic properties. Natural mordenite is more resistant towards ion exchange and it needs further modifications. However, the crystallinity increased upon the treatments maybe due to washing out of the amorphous extra framework species.

\section{ACKNOWLEDGEMENTS}

The authors acknowledge Spanish Government, MINECO (MAT2012-31127) and the Spanish Research Council CSIC (i-COOP014) for funding. ID acknowledges the CSIC for the research leave at Addis Ababa University. WM acknowledges Dilla University for support. The Chemistry Department, Addis Ababa University is also acknowledged for financial support.

\section{REFERENCES}

1. Sharma, P.; Chung, W.J. Desalination 2011, 275, 172.

2. Lee, S.H.; Shin, C.H.; Hong, S.B. J. Catal. 2004, 223, 200.

3. Auerbach, S.M.; Carrado, K.A.; Dutta, P.K. Handbook of Zeolite Science and Technology, Marcel Dekker, Inc.: New York; 2003; p 50.

4. Apelian, M.R.; Fung, A.S.; Kennedy, G.J.; Degnan, T.F. J. Phys. Chem. 1996, 100, 16577.

5. Sherman, J.D. Proc Nat. Acad. Sci. USA 1999, 96, 3471.

6. How, H. J. Chem. Soc. 1864, 17 (new ser.), 100.

Bull. Chem. Soc. Ethiop. 2015, 29(1) 
Mild modification method for generation of mesoporosity in synthetic and natural mordenite 103

7. Baerlocher, E.C.; Meier, W.M.; Olson, D.H. Atlas of Zeolite Framework Types, 5th ed., Elsevier: Amsterdam; 2001.

8. Song, C.; Schmitz, A. D. Sekiyu Gakkaishi 1999, 42, 287.

9. Van Laak, A.N.C.; Sagala, S.L.; Zecevic, J.; Friedrich, H.; De Jongh, P.E.; De Jong, K.P. J. Catal. 2010, 276, 170.

10. Laak, A.N.C. van.; Gosselink, R.W.; Sagala, S.L.; Meeldijk, J.D.; de Jongh, P.E.; de Jong, K.P. Appl Catal A-Gen. 2010, 382, 65.

11. Groen, J.C.; Sano, T.; Moulijn, J. A.; Pérez-Ramírez, J. J. Catal. 2007, 251, 21.

12. Boveri, M.; Márquez-Alvarez, C.; Laborde, Ả. M.; Sastre, E. Catal. Today 2006, 114, 217.

13. Aslam, W.; Siddiqui, M.A.B.; Rabindran, J.B.; Aitani, A.; Čejka, J.; Al-Khattaf, S. Catal. Today 2014, 227, 187

14. Serrano, D.P.; Escola, J.M.; Pizarro, P. Chem. Soc. Rev. 2013, 42, 4004.

15. Li, H.; Li, M.; Chu, Y.; Nie, H. Micropor. Mesopor. Mat. 2009, 117, 635.

16. Müller, M.; Harvey, G.; Prins, R. Micropor. Mesopor. Mat. 2000, 34, 135.

17. Holm, M.S.; Taarning, E.; Egeblad, K.; Christensen, C.H. Catal. Today 2011, 168, 3.

18. Ayalew, T. Modification of Zeolite $Y$ for Catalysis, M.Sc. Thesis, Addis Ababa University, Addis Ababa, Ethiopia, 2012.

19. Jentys, A.; Lercher, J.A. Techniques of zeolite characterization in Introduction to Zeolite Science and Practice, 2nd ed., van Bekkum, H.; Flanigen, E.M.; Jacobs, P.A.; Jansen, J.C. (Eds.), Elsevier: Amsterdam; 2001.

20. Brunauer, S.; Deming, L.S.; Deming W.E.; Teller, E. J. Am. Chem. Soc. 1940, 62, 1723. 